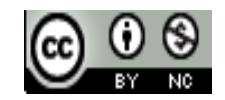

Journal of Education, Teaching, and Learning is licensed under

A Creative Commons Attribution-Non Commercial 4.0 International License.

\title{
SYNECTICS MODEL: AN OfFER TO DEVELOP STUDENTS' CREATIVITY THROUGH SCIENCE LEARNING
}

\author{
Tomo Djudin \\ Tanjungpura University, Pontianak, Indonesia \\ E-mail: tomo.djudin@yahoo.com
}

\begin{abstract}
Creativity plays an important role in everyday life. The main basis for the emergence of creativity is the use of existing knowledge imaginatively (creatively) to produce a new, unusual, and useful product. Interpretation of a problem in a new and different way (restructuring) and incubation is an additional basis for the emergence of creativity. The Synectics model is designed based on two main strategies: (1) Designing something (problem, idea, product) that has been previously known to be something new; and (2) Creating something new becomes more known and meaningful.
\end{abstract}

Keywords: Creativity; Creativity Base; Brainstorming; Synectics Model

\section{INTRODUCTION}

In this life, change is a necessity. Rapid change in many areas of life results in the complexity of the problem and the uncertainties of the present world situation ascertained (very) different from previous times. Naturally, if the education system around the world continues to change to anticipate the changes (science and technology, social, cultural, economic, political) that will occur in the future. Education is believed to be a determinant of the progress and prosperity of a nation. Changes in the educational system are needed to prepare the human resources of a nation (community) in order to be able to meet requests and unexpected demands in the future.

One of the central human resources of all innovation educational endeavor is learners (read: students). To prepare students to anticipate future demands and demands, educational goals in all educational settings are oriented towards improving students' skills in the cognitive domain (if thinking), affective domain (though attitudes/ethics), and psychomotor domain (physical). UNESCO (UN agency that deals with education and culture) has outlined the education pillars that should be built through a policy and innovation efforts of a nation's education: learning to be, learning to live together (MoNE, 2001).
Another ability that students need in their daily lives is their creative ability or creativity. Gordon (in Joyce \& Weil, 1986) emphasizes that "creativity as a part of our daily work and leisure lives". Training students' creativity can make a significant contribution to the flexibility and ability to handle changes in their lives/work. Incorporating an increase in student creativity in learning objectives and educational curriculum is important. Morten \& Vanessa (2007), asserts that every subject in the school should emphasize creativity, on an agenda that reflects its own characteristics. Beaton (in Morten \& Vanessa, 2007) considers "creativity as 'very important' for success in school science." With practice and the provision of learning conditions, carefully designed will enable students to produce something "new" and work in accordance with the demands or desires.

Although it is believed to be very important, creativity has not been fully addressed as a major topic in educational research and has not yet been placed in an important position in educational practice (learning) in schools. This is not only happening in the homeland but also abroad (Boden, 2001, in Morten \& Vanessa; 2007). There are at least two causes. First, the instructional practices aimed at understanding and mastery of teaching materials conceptually (cognitive domains), both by teachers and students, can still be "questioned". The density of 
teaching materials that teachers must convey according to the demands of the curriculum is another reason. With such barriers and constraints, the development and/or integration of cognitive domains with affective (improved attitudes, ethics) and psychomotor (improvement of motor skills), and the development of student creativity are reasonable. Whatever the condition and practice of learning in the class are not expected to "kill" the creativity of students. Secondly, what creativity really is and how to design or develop learning that can provide conditions for students' creativity improvement is believed to be largely unknown and understood by teachers. Tilaar (1999) reminded that if there is an innovation of education and efforts to improve the quality of education should be done on a micro scale, which is school-based class (touch directly teachers). This is rational considering the teacher is one of the determinants of the quality of education and the high low level of student learning outcomes in school.

This paper presents briefly some of the things related to creativity, among others; what creativity really is, the concept of creativity and scientific creativity in science (IPA), teaching for creativity versus creative teaching, and brainstorming and synectics models are offered to enhance students' creative thinking. Paradigm creativity and learning model that will be presented further expected later can be developed by the teacher themselves.

\section{Methodology}

The method used in this research is literature study. The data used comes from various sources such as reference books, scientific journals derived from research publications conducted by experts, articles, and websites related to the research topic. This method is used to understand more about research topics based on literature that discusses important matters relating to research.

\section{DISCUSSION}

Creativity in Cognitive Psychological Perspective and The Factors that Influence It

According to some psychologists, creativity is a quality or personal trait (trait). Stenberg \& Lubart (1999, in Morten \& Vanessa, 2007) states that the ability to produce new (novel) and appropriate works. Others mention that creativity is not a personal trait (innate), but is a skill or process that produces "creative" products, for example; painting, invention, computer program, or solution becomes a personal matter. Creative people, according to Gardner (in Woolfolk, 1995), someone who regularly solves problems, designs a product or defines a problem in a domain (field) in such a way that it is considered to be a new product. Concepts or fields related to creativity, among others; intelligence, gifted, art, literature, engineering and genetics, problem-solving, divergent thinking skills, and creative writing. Imanjinatif products, considered new (novel), and original (original) in a particular field is the work of high creativity. Referring to some literature related to creativity, Morten \& Vanessa (2007) mentions that there are 4 (four dimensions) creativity, ie creative people, products, processes, and environment.

One process that can enhance creativity is brainstorming (Matlin, 1994: 368). Brainstorming is a process done in a group that is guided by four basic guidelines; namely: (1) Evaluation of ideas should be done at the end of group activities; therefore, criticism is avoided; (2) The more "wild" an idea, the better. It is easier to "tame" an idea than to bring it up; (3) The more ideas that come up, the better; and (4) People can combine two or more ideas that others propose. The spirit of brainstorming sessions is considered important and necessary, especially when accompanied by the creation of a friendly atmosphere and in a relaxed (pleasant) frame of mind. It is stated that the effectiveness of brainstorming in enhancing creativity has not been supported by sufficient evidence or research results. Woolfolk (1995: 307) asserts that "the basic tenet of brainstorming is, because of the evaluation of often inhibits creativity and problem solving".

Another factor that influences the increase in creativity is the social environment. A person can be creative both in working together (group) and working alone. However, asking someone to evaluate work (so that an employment or work is judged to be technically incompatible or unrecognized) can potentially reduce creativity. Amabile (1990, in Matlin, 1994), mentions the social (environmental) factor may decrease or decrease a person's creativity under the following conditions; (1) When someone is watching you are working; (2) When you are offered a reward for being creative; (3) When you are competing for a prize; and (4) when a person blocks or limits your choices to express your creativity.

Stenberg (1985, in Woolfolk, 1995) explains that creativity comes from the use of knowledgeacquisition components in a clear way. The basis for creativity is to have extensive knowledge in a field. Another necessary knowledge is the ability to change (restructuring) problems in new (different) ways that will lead to sudden clarity (insight). Often, this sudden clarity occurs when a person has tried hard to solve a problem and fails, then he can solve it all of a sudden. A sudden solution is called incubation of an unconscious form of work when one deals with a new (unknown) problem (Woolfolk, 1995: 304). Yaniv \& Meyer (1987, in Matlin, 1994: 370) explains that incubation will occur when a person is solving a difficult problem and an interval between the time period of intense work and the next working period. 
According to Matlin (1994: 364), creativity is an area of problem-solving, but "problem-solving sounds so routine, whereas creativity sounds inspired". Creativity is the creative process of thinking to get "light bulbs above its head". He also asserted that most experts agree that novelty is an important element of creativity. Another element that is a requirement of creativity is the achievement of a goal or solution of practical problems (practical), unusual (unusual), and useful (useful).

Cognitive psychologists propose a diverse definition of creativity. In fact, some of them are disagreeing, arguing, criticizing with a definition or a way of measuring creativity. However, they agree in supporting and appreciating the proposed definitions and instruments of creativity as well as efforts made to enhance creativity (Matlin, 1994: 368; Morten \& Vanessa; 2007). There are several tests that experts recommend to measure creativity. Guilford (1967) developed the Divergent Production Tests. Mednick \& Mednick (1967) have designed The Rote Associates Tests (RAT). Amabile (1983) has developed the technique of Consensual Assesment Technique (see Matlin, 1994: 365-368). To measure students' creativity in the classroom, teachers can use The Rating Scale of Creativity by Jerome Sattler, 1992 (see Woolfolk, 1995: 307).

Teaching for Creativity (Scientific) vs Creative Teaching

As a result of the absence of an "approach" or "definition" generally considered "right", as well as a domain will use different interpretations or concepts of creativity, Morten \& Vanessa (2007) proposes the concept of "scientific creativity) "In the context of science education. The concept of scientific creativity is expected to tolerate the use of sometimes elusive and diverse concepts of creativity. In addition, according to Morten \& Vanessa (2007), most of the science education literature uses the label "creativity, only as descriptive," because it is not truly investigating creativity. They propose two criteria of scientific creativity. First, scientific creativity must be based on the activities of real scientists. Scientific and scientific creativity in schools must take root and reflect the creativity aspect seen from scientific research. Second, any scientific creativity approach should develop a framework that fits the needs and abilities of students.

In science education, there is a difference between "teaching for creativity" and creative teaching "(NACCCE, 1999, in Morten \& Vanessa, 2007). The first places creativity as a result of learning, while the second is only a characteristic of teaching. Morten \& Vanessa, 2007) added that creative teaching is an imaginary use by teachers to create more engaging, enjoyable, and effective learning. Creative teaching is related to "open-ended, student-oriented, exploratory, and group-based learning strategies, including" hands-on activities in the laboratory or outdoors ". It should be understood, however, that creative teaching is not limited in one particular context (eg laboratory, class, out of class, working in groups, or individually), but on the ways in which teachers manage and organize learning.

It is an inquiry and discovery approach that is often referred to and found in many scientific educational literatures regarding creative science teaching (see Trowbridge \& Bybee, 1990; Carin \& Sund, 1995). Scientific inquiry is considered in line with the nature of science, as a process and a product. Scientific inquiry reflects what a real scientist does in developing a scientific product (concept and principle). The issue is whether inquiry-based science teaching-which is still a slogan of creative science teaching in many developed countries (read: the United States and Britain), really offers an arena for the development of students' scientific creativity still debated. Anderson (2002, in Morten \& Vanessa, 2007), for example, concludes, in general, research shows that inquiry teaching produces positive results. In contrast, the results of Welch's research, et al. (1981) who analyzed the role of mercury in the science of science in the United States from 1960 to 1980 documented a "gap" between "desired state" and "what / real situation". What really happened is still very far from what is expected. Strong evidence related to the conflict of effectiveness is allegedly often ignored. In the UK, the study of Donnelly et al. (1996) evaluated the science education curriculum from 1980 to 1990 by asking students aged 11-16 to conduct individual investigations (in the Science I Program), concluded that scientific investigations fundamental ill-understood students (ill-conceived). In a study by Bills (1971), which links creativity and inquiry science, involving as many as 306 14-yearold students of grade 14 in quasi-experimental research (experimental groups were trained on "diverging thinking" through open-ended inquiry tasks inquiry tasks), concluded that the training had no effect on the ability to complete the tasks given. There were two explanations of Bill related to these findings. The training was not able to develop the creativity and creativity developed in the task of science cannot be transferred to the tasks tested.

The results of the study presented in this paper may provide an empirical message or fact that the application of inquiry science-based science strategies in science subjects (IPA) does not guarantee an increase in students' scientific creativity. The excessive belief of a researcher (teacher) on the effectiveness of the application of science inquires (external factors, experimenter biases) to improving students' scientific creativity will, for example, potentially provide unnatural (pretend, irrational/honest) treatment to experimental groups to "prove "What he believes. Internal validity of experimental research can also be influenced by instrumentation factors. The designed research 
instrument should really be able to measure what should be measured (reliable). Define operational variable research using observable criteria based on relevant theories also determine the validity of research instruments.

Synectics Model: An Offer

The synectics teaching model was developed by William Gordon (1961). This model is based on 4 (four) thoughts/ideas that contradict the conventional insight on creativity. First, creativity plays an important role in everyday life. This model is designed to improve problem-solving skills, expressing creative ideas, empathy, understanding in social relationships. The meaning of an idea can be enhanced through creative activity. Second, the creative process is not a mysterious thing. The creative process can be described and directed to others directly to enhance their creativity. Gordon assumes that if individuals understand the fundamentals of the creative process, they can understand that understanding to increase creativity freely in their life and work. Creativity can be improved through a conscious analysis that directs it to describe and create training procedures that can be implemented in schools and in other settings.

Third, creativity discovery is the same for all fields (not only in art) and is characterized by the underlying intellectual process similarities. Fourth, Invention/discovery (creative thinking) both individually and in groups has in common. Individuals and groups generate ideas in a similar way/pattern. Creativity is not merely a personal experience, but it can be donated (be shared) with others.

The special process of synectics is developed from a number of psychological assumptions. The first assumption is to engage students in the creative process consciously and by developing creative aids, we can enhance individual and group creativity. The second assumption is that the emotional component/element is more important than the intellectual element, the irrational element is more important than the rational departure. Irrational circumstances are the best mental environment for exploration, expansion, the emergence of fresh ideas. The third assumption is the emotional element, the irrational element must be understood to increase the likelihood of success in problem-solving (Gordon, 1961, in Joyce \& Weil, 1987). Thus, the analysis of irrational and emotional processes can help individuals and groups enhance creativity through the use of irrationality constructively. Gordon's assumptions are in line with the social factors that influence creativity (see Amabile, 1990) and the brainstorming process. Irrational aspects can be understood and controlled consciously using metaphors (metaphors) and analogy (analogy). Both are synectics objects. Through both, the process of creativity becomes a conscious process (conscious process).

The metaphor is the process of building a relationship of similarity, the comparison between an object/idea with another object/idea, placing the first object in place of the other object/idea. Through this substitution the creative process will emerge, connecting an idea known to the unknown, or creating a new idea from the old (previous) idea. Metaphors contain conceptual distances between students and objects or teaching materials. Metaphors give signs of original (original) thinking. The following are examples of metaphors: From what has been known to something new (what you think, if your textbook is an old shoe or a stream "), from the new to something already known (" What do you think, if the body You as a transportation system ").

The second synectics object is the analogy. There are three forms of analogy that can be used as the basis of the synectics exercise, namely: personal analogy, direct analogy, and compressed conflict. In personal analogy, students are asked to be part of the physical elements of a problem or object (person, plant, animal, or inanimate object). Personal analogy emphasizes empathetic engagement. Example, "Be a car engine. How do you feel?. Describe your feelings when you are turned on in the morning; when your battery runs out; when you arrive at a red light (stop sign)! "Explain how air pressure like you are in a small room and many people"

The direct analogy is a simple comparison of two objects or concepts. The comparison should not be identical in all aspects. The function of the compromise is only to change the conditions of the actual situation of the topic or problem into another situation to bring up new ideas. Identification can be against people, plants, animals, or inanimate objects. For example, "concave lenses show what kind of personality", how to achieve success such as peeling onion skin; "What if a polar bear is like a cold yogurt drink"; "What is the state of energy in the system when compared to the body's sprinkling system (excretion); ".

Conflict compression, in general, describes an object using two opposite words or contradicting one another. Conflict compression reflects students' ability to combine two terms of reference against a single object. The wider the distance between the two terms of reference, the greater the mental flexibility. Example: "A friendly enemy"; "Life-saving destroyer" "soft aggressiveness".

Here will be presented syntax (steps) learning model synectics as follows. There are two strategies or teaching models based on synectics.

The first strategy: creating something new, designed to make something known (problems, ideas, products) into something new or with a creative point of view. 
First Strategy Syntax of Synectics Model :

Creating something that is already known becomes something new

Phase 1 : Describe the current conditions

The teacher asks the students to describe the situation or topic when they see it now.

Phase 2 : Direct Analogy

Students suggest a direct analogy, choose one and explore (describe) it further.

Phase 3 : Personal Analogy

The student "becomes" like the student's chosen analogy at phase 2.

Phase 4 : Compression Analogy

Students use their descriptions from phases 2 and 3 and suggest some conflict analogy, and choose one of them.

Phase 5 : Direct Analogy

The student makes and chooses another direct analogy, based on the analogy of the compression conflict.

Phase 6 : Re-test the original task

The teacher asks the student to go back to the task, topic, the original problem by using the last analogy and/or the whole analogy.

Second Strategy: creating something new or an unknown idea into something more meaningful (more familiar).

Second Strategy Syntax of Synectics Model :

Creating something new becomes something more known

Phase 1 : Substantive Input

Teachers provide information on new topics.

Phase 2 : Direct Analogy

Students suggest a direct analogy and ask students to describe the analogy.

Phase 3 : Personal Analogy

The student "becomes" like the student's chosen analogy in phase 2.

Phase 4 : Comparing Analogy

The student identifies and explains the points of similarity between the selected topic and the direct analogy.

Phase 5 : Explain the differences

Students explain why the analogy they made does not match the chosen (new) topic.

Phase 6 : Creating an Analogy

Students present their own analogy and explore (search for) similarities and differences.
To get a clearer picture, it is helpful for teachers interested in applying synectics model syntax to read examples of learning scenarios presented in Models of Teaching (Joyce \& Weil, 1987: 159 - 163).

There are two effects that are expected from the application of the Synectics model, namely the effect of learning (direct) and co-effect. In terms of learning effect (instructional), this model is expected to improve the general creative ability and creative ability of the teaching material domain. Meanwhile, the effect of the attachment is the increase of learning result of a teaching material and cohesion togetherness and increase productivity.

\section{CONCLUSIONS}

In fact, no single method, model, approach to teaching, any other term, is considered "the best and most suitable" for all the conditions (context) and teaching materials. The implication is, it needs pedagogical consideration in selecting and applying a teaching model. For example, regarding the characteristics and content of teaching materials, time allocation, objectives, availability of facilities and infrastructure, student characteristics, and desired effects. In this context, the modification of a teaching model, perhaps very, is needed for its application to be more effective and efficient.

The courage to try to apply a learning model will provide a meaningful "personal experience." Experience and willingness or spirit to improve ourselves continuously this is what became, one of, factors that influence the improvement of the quality of a teacher.

\section{REFERENCES}

Carin \& Sund. 1995. Teaching Modern Science. New Jersey: Merril Prentice Hall

Joyce, B. \& Weil, M. 1987. Models of Teaching ( $3^{\text {rd }}$ edition). New Jersey: Printice-Hall, Inc.

Depdiknas. 2001. Dengan Buku Jelajahi Dunia. Buletin Pusat Perbukuan.

Matlin, M.W. 1994. Cognition. ( $3^{\text {rd }}$ edition). Florida: Harcourt Brace Publishers.

Morten, P. \& Vanessa, K. 2007. Creativity in Science Education: Perspectives and Challenges for Developing School Science. (http://www.redorbit.com/news/science/91532 0/ Creativity_in_Science Education_ Perspectives_and_Challenges_for_Developing School/index.html).

Tilaar,H.A.R. 1999. Beberapa Agenda Reformasi Pendidikan Nasional dalam Perspektif Abad 21. Magelang: Tera Indonesia. 
Trowbridge, L.W \& Bybee, R.W. 1990. Becoming a Secondary School Science Teacher $\left(5^{\text {th }}\right.$ edition). Columbus, USA: Merril Publishing Company.

Woolfolk, A.E. 1995. Educational Psychology (6 ${ }^{\text {rd }}$ edition). Boston: Allyn and Bacon. 